\title{
Cosmopolitanism and Multilingualism in a Globalized World: Perspectives on the Lack of Foreign Language Learning in the US
}

\author{
Kathleen Stein-Smith \\ Fairleigh Dickinson University, Metropolitan Campus, Teaneck, NJ, USA
}

\begin{abstract}
Although cosmopolitanism has a long history, it has become even more relevant in the global era and, especially, since the COVID-19 global pandemic has made communication and understanding across cultures more important than ever. Multilingualism is the essential cosmopolitan skill and tool, empowering those who are proficient in one or more additional languages to understand, and to communicate and interact with others more effectively. The United States suffers from a foreign language deficit, and there is an urgent need to build both motivation and interest in other languages along with sustainable skills in other languages in the US. Steps to effectively address this deficit include prioritizing language learning and use, and providing the opportunity to all interested students to learn one or more additional languages.
\end{abstract}

Index Terms - multilingualism, cosmopolitanism, global identity, global citizenship, language learning

\section{INTRODUCTION}

"We are at an extraordinary moment in human history. Cooperation within and across borders is vital as we work to solve global challenges. Clear and precise communication is more crucial than ever before to the health and security of every nation" (AMACAD, 2020, 1). This powerful call to action by five international academies, representing Australia, Canada, the United Kingdom, and the United States (in alphabetical order), is the most recent affirmation of the role and significance of languages in a global context. Cosmopolitanism, often thought of as citizenship of the world or global/cosmopolitan citizenship, and described as feeling "at home in the world" (Brennan, 1997, title), has become increasingly important in an interconnected and globalized world, and this importance has been highlighted during the COVID-19 global pandemic, which has underscored both the commonalities of needs and concerns in all parts of the world, along with the need for international cooperation and collaborations in the search for solutions to complex global issues.

While cosmopolitanism may at first seem an abstract concept, it simply means that the idea that all human beings are, can, and should be citizens in a single worldwide community. In a globalized and interconnected world, the ability to communicate with others in our global community is an essential and a critical skill. In addition, in our own local society, knowledge of heritage languages is not only a way to maintain ties to our own personal cultural identity and to communicate with family members, it is also a way to build and strengthen ties among diverse groups in our society, thereby increasing harmony and reducing segmentation, and to build interest in the broader world. Language learning and the use of additional languages in our homes and communities, in the workplace, and in our society, are ways in which we can develop the multilingual skills that can enhance our international mindset and facilitate the development of global citizenship values. "Language skills foster literacy, educational attainment, and a confident mindset that views cultural difference with curiosity rather than prejudice" (AMACAD, 2020, 2).

The call to action by the five international academies is all the more noteworthy in that it comes from the anglosphere, and English-speakers tend to be among the least likely to learn additional languages. US students tend to lag behind those in many other countries in language skills, and this language gap, or language deficit, impacts on international relations, international business, and on the ability of Americans to interact effectively in the world, either as tourists and travelers, or as global citizens on the world stage, as well as on intercultural understanding and harmony in our increasingly multilingual society in the US (Devlin, 2018; Stein-Smith, 2013).

The philosopher Wittgenstein is considered to have led the contemporary conversation on multilingualism and identity, as well as the linguistic turn -- which has focused on the significance of language in the individual rather than on language merely as a system -- writing a century ago that "the limits of our language are the limits of our world" (Gunesch, 2003, 227). However, the relationship between language knowledge and global identity and the significance of multilingualism in the development of an international mindset and global citizenship values, the value of language skills in problem-solving and creativity, and in transnational teams, as well as the role and nature of multilingualism within the individual are still aspects in need of consideration and examination (Kharkhurin, 2012; Livermore, 2016; Gunesch, 2008). The role of bilingualism in the life of the bilingual and bicultural individual is another area where multilingualism and individual cosmopolitan identity meet (Grosjean, 2019). 
In an increasingly interconnected and globalized world, effective communication is of critical importance, and multilingualism is an essential skill in developing an international mindset and global citizenship skills. Knowledge of another language offers an unparalleled window into another culture. However, while the United States is a nation of immigrants, remarkably few Americans speak an additional language. The US suffers from a foreign language deficit, with only 1 in 4 Americans able to have a conversation in a language other than English and with fewer than $20 \%$ of K12 students, and $7.5 \%$ of college and university students studying another language (McComb, 2001; American Councils, 2017; MLA, 2019). While US students lag behind students in other countries in language learning and language skills, this is all the more surprising in light of our US history as a nation of immigrants. The causes for this are many, including the belief among many US students that English is the global lingua franca and that other languages are not necessary, further reinforced by the British narrative through which US history has traditionally been told, learned, and taught.

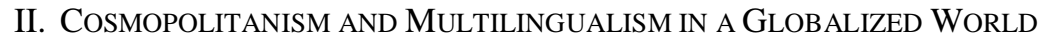

People have always traveled, and their languages have been in contact throughout history -- with Herodotus and The Odyssey among the best-known examples from classical history, followed by Erasmus during the Renaissance, along with countless others who traveled for military, political, and economic and other reasons, and the many explorers of different regions and time periods. It is interesting to note, and no coincidence, that the European Union student exchange program is the Erasmus Programme, and most recently Erasmus+. In more recent time, travel has been made easier through technological advances, and has become more accessible -- available to a large segment of the general public, and the "Grand Tours" of yesteryear have become study abroad and study away.

As people have travelled, their languages have been in contact -- to the extent that linguists, most notably Uriel Weinreich, have studied language contact, and the changes that these contacts have caused over time throughout history, with the case of the influence of French on the English language through the Norman Conquest among the best known examples. Over the course of several centuries, this contact resulted in the fact that nearly half of the modern English lexicon, or vocabulary, is of French origin.

Along with this ongoing contact among people and their languages throughout history, the idea of cosmopolitanism has evolved, from the ancient world through the Enlightenment, and into the 20th century and beyond, through institutions like the UN and through the lenses of moral, political, philosophical, cultural, and economic cosmopolitanism. Contemporary author Kwame Anthony Appiah may sum it up best, with "conversations across boundaries can be delightful, or just vexing, what they mainly are, though, is inevitable" (Appiah, 2006, xxi). This inevitability of conversations across cultures forms the foundation for the conversation about the necessity of multilingualism in an increasingly interconnected and globalized world where language skills offer unparalleled access into the world of another cultures, empowering the person who speaks more than one language to communicate directly with those of another culture during travel and study abroad, in international business and the globalized workplace, as well as in our local neighborhoods.

While this interaction of languages in contact has brought about visible changes to the languages in question, with the influence of French on English as one of the best-known historical examples, the interaction of multiple languages within the individual may have varying effects on the personal cultural identity of that individual. This relationship of multilingualism to cosmopolitanism or global identity is of interest not only to educators, but to all who believe in and work toward a better world through better mutual understanding (Gunesch, 2008). An example of the interplay of languages and identities in the educational setting is the discussion of French, American, and global identity at the Lycée Français de New York (Ross, 2019). An example of this interaction among postsecondary students within the context of a global youth forum and a UN activity is the Many Languages One World global youth forum (United Nations, 2017).

Moreover, the very process of language learning generally involves learning a great deal about the culture of the target language(s) through direct exposure to and discussion of authentic texts and media reflecting not only the language, but also the beliefs and values of the other culture. This ability to read both non-fiction, biographies, scholarly journals, and popular newspapers and magazines in another language, as well as fiction and other literature helps the multilingual to develop a more accurate and nuanced understanding of another culture than could be acquired by reading works written by outsiders to the culture and/or translated into English. Listening to or watching the news or a documentary, watching a popular television series, or enjoying a film without needing to depend on subtitles or dubbing which, at best, add an additional barrier between the viewer and the content, are just a few of the many benefits. The good news is that, due to technology, it is easier today than ever before for everyone interested in viewing the world from different perspectives to access news, information, education, cultural events, and entertainment through different cultural and linguistic lenses.

The power of the media, and the role of the multilingual celebrity, are significant. Well-known figures in history around the world have been multilingual, including US Founding Fathers Thomas Jefferson, Benjamin Franklin, and others. Contemporary US public figures, including John Kerry, Mitt Romney, and Antony Blinken, have been fluent in at least one other language (in these cases, French), as are US celebrities like Serena Williams and Bradley Cooper, with other well-known Americans like Mark Zuckerberg and Sandra Bullock speaking Chinese and German 
respectively. These examples are just a few of the many which can potentially inspire and motivate language learning among Americans. In addition, non-English language television series like "Casa de Papel," "Dix pour cent/Call My Agent," and "Lupin" have had considerable popularity in the US, and the appeal of popular media and entertainment can also be used to leverage interest and motivation to learn more about other languages and cultures. However, this interest in celebrities and in entertainment media, while invaluable in motivating sustainable language learning, may not necessarily lead to an objective overview of another language and culture, and needs to be supplemented by structured reading and learning across the disciplines.

Migration has always existed, and it is paradoxical that the US, a nation of immigrants, is a nation where relatively few English speakers are able to hold a conversation in a language other than English. Reasons for this include the "melting pot" metaphor prevalent during much of US history, which encouraged assimilation and language loss. However, many Americans are aware of a non-English speaking culture in their family story even if they may not speak that heritage language at this time, sometimes after many generations, or a few, in the US, and at present, over 70M in the US speak another language in the home (Ryan, 2013). Interest in one's family language(s) has the potential to lead to language and cultural learning now and in the future, and to the development of a more international mindset.

\section{Multilingualism AND COSMOPOLITANism in A Multilingual WorLD}

"Language is a critical instrument that shapes one's view of the world. Understanding the meaning of the words other people use yields perhaps the most insight into cultural differences" (Adams \& Carfagna, 2006, 174). While in the US, the traditional narrative highlights the primary role of English, a legacy of British colonialism, as the de facto language of the United States, the global reality is that at least half of the world population speaks more than one language on a regular basis (Grosjean, 2010,2020), and that only 25\% of the world population speaks English (British Council, 2013). Bilinguals and multilinguals around the world can also be viewed as those who have been students in schools where additional languages are taught as foreign languages, or those where more than one language has been used as the medium of instruction -- foreign language learning versus bilingual/multilingual education. While cosmopolitanism and the development of a cosmopolitan worldview, identity, and values may not be linked to the number of languages spoken by the individual, the level of linguistic skill, the number of languages -- or which languages --are spoken, "arguably there are limits to an individual's cosmopolitan development if he or she does not have a set of languages to start with" (Gunesch, 2003, 227).

The US lags behind in terms of multilingualism for a variety of reasons -- foreign language instruction begins relatively late, may not be required, and may not be sufficiently intense (Devlin, 2018; Pufahl, Rhodes, \& Christian, 2001). Again, reasons for this are varied, ranging from a lack of interest and motivation among many who may consider English, the global lingua franca, sufficient, but also a lack of opportunity in the US for interested students to learn another language partially caused by the lack of a language policy, with a decreasing number of an already-small percentage of public elementary and middle schools offering language programs (Stearns, 2008; AMACAD, 2017). It is this lack of opportunity which is the most troubling, and becomes a question of equity, as bilingualism has been shown to benefit especially lower-income and immigrant children and (Izadi, 2014; Hu, 2018).

While the US does not have an official language, many international organizations do, including the United Nations, the International Olympic Committee, the European Union, and many more. Although the specifics of multilingualism may vary, the goals remain communication and understanding across cultures. In the UN, while there are over 190 members, six languages -- Arabic, Chinese, English, French, Russian, and Spanish (in alphabetical order) are official languages; and English and French serve as working languages of the UN Secretariat. Many UN publications are translated into additional languages, and in order to further support multilingualism, the UN supports individual languages on specific days throughout the year, as well as various initiatives including the Many Languages One World (MLOW) Global Youth Forum (United Nations, 2017). French and English are the official languages of the IOC, along with local language of the Games. Interestingly, the Organisation internationale de la Francophonie (OIF) delegates a Grand Témoin to the Olympics to ensure that French is being utilized to its full extent as an official language. The European Union, with a core value of multilingualism, considers the official language of all member nations as official languages while using English, French, and German as working languages. Within the context of multilingualism, plurilingualism, or the ability to function in communicative situations in more than one language, is especially important (Lüdi \& Py, 2009). In the Brexit era, the continued future role of English in Europe has been a topic of discussion.

Languages have different degrees of influence, based on historical, political, and economic factors, which evolve over time. While many languages are used in more than one country, French and English are generally considered global languages, with France and its language widely known for "soft power," or influence. Artificial or created languages, including Esperanto, have been created, intended to serve as second languages to enhance global communication. Multilingualism also means valuing local languages, ensuring that all students have the opportunity to learn additional languages, and eliminating the commodification of language learning (Holborow, 2018). The most important factor is that "the necessity of foreign-language education could not be clearer right now. The future in America, and everywhere, is multilingual. And so is the present" (Montlaur, 2019, web). 
Many Languages One World (MLOW) is an example highlighting "global citizenship and cultural understanding, and the role that multilingual ability can play in fostering these" (UN, 2017, web). Including an essay contest in which college and university students from around the world write essays in a learned second language which is also one of the official languages of the UN on the significance of multilingualism in global citizenship. Essay contest winners -generally 10 for each of the 6 official languages of the UN -- have been invited to a week-long youth forum on a US campus where they live in a global community and work within their language groups, following a process of appreciative inquiry. This is intended to engage the participants in self-determined change in a positive environment, bringing together a large and diverse group of student winners together to study and build upon their best ideas, as they develop their presentations of action plans to implement the Sustainable Development Goals (SDGs) that are delivered in the UN General Assembly Hall -- all of this in the learned second language of their winning essay. While the experience has been meaningful for both the student winners and the staff who worked with them to facilitate the development of the presentations, the lasting impact would be the relationships formed among the students and which have been continued through social media, local mini reunions, and informal encounters, and more recently, through online reunions and discussions of future projects inspired by the Sustainable Development Goals (SDGs), emphasizing the importance of the final goal, Goal 17, "Partnerships for the Goals," which strongly implies multilingualism and communication across cultures.

\section{Encouraging Multilingualism and Becoming Multilingual: The Role of Language Learning And LANGUAGE USE}

"Learning another language offers a different view of the world" (Adams \& Carfagna, 2006, 174). While over half of the world population is multilingual, using more than one language on a regular basis, and $75 \%$ of the world population is not proficient in English, English-speakers -- including Americans -- remain relatively unlikely to be able to hold a conversation in a language other than English (Grosjean, 2010,2020; British Council, 2013; McComb, 2001). In a multilingual, globalized, and interconnected world, where knowledge of languages is both the means to better understand other cultures and also the tool to communicate and to work together with others, the challenge is to foster and encourage multilingualism in the US.

Two aspects of multilingualism that need to be considered and examined are language learning and language education in order to build and strengthen proficiency, and perhaps even more importantly, language use in order to provide the opportunity to use language in authentic communicative settings and for authentic communicative purposes in the workplace and in our society. Traditionally, the conversation on language and languages in the US has traditionally centered primarily on language learning, but real-life opportunities to use other languages in meaningful ways would not only strengthen skills, but would also incentivize the time-consuming and difficult task of learning other languages.

Central to both language learning and language use is motivation, and creating sustainable motivation is key to successful outcome in language learning. Motivation can be as varied as individual personalities and interests, including interests in history, literature, music, the arts, and the lifestyle of another culture; one's own cultural heritage and family story, or that of a friend or loved one; as well as career and professional plans and goals. Intrinsic motivation, or genuine interest in another culture, is generally considered the most effective motivation (Dornyei, 1994). Areas in need of planning include awakening interest in other languages and cultures, and creating pathways to educational programs with a global and/or multilingual dimension.

The process of awakening interest in other languages and cultures involves us all, as individuals, as members of our communities, and as citizens. Methods can be as varied as are all our communities and their members, including initiatives, events and media intended to appeal to a broad range of interests, to all ages, and -- most importantly -- to all levels of experience with the target language and culture. Heritage languages and cultures have the potential to attract those who may not be considering language learning or international education. While the questions of language use and fluency may arise, at this stage, the most effective events and initiatives are inclusive, with the goal of reaching the largest number of participants. Additional community activities can foster additional development through more targeted activities, language learning, and use of the target language. The power of creativity, either active creativity or enjoyment of media and entertainment, is significant and can form the foundation of sustainable engagement in both language and cultural learning. The 4Cs of global learning -- communication, collaboration, critical thinking, and creativity -- are a useful framework for developing both multilingualism and cosmopolitanism (Pardede, 2020).

In terms of educational programs, which would at the same time build language skills and sustain interest at all levels, it is necessary to consider both curriculum and availability (AMACAD, 2017). For students at younger ages, it is necessary to ensure availability of continued foreign language learning, especially in public schools, in order to reach the largest number of students. At the postsecondary level, it is important to build K-16 collaborations which would strengthen continuity, and to develop programs including not only foreign language and international/global studies, but also interdisciplinary partnerships and joint programs, in order to empower students across the disciplines to develop pre-professional proficiency and skills. Whether in our communities or in our educational institutions, in order to encourage multilingualism, it is essential to encourage both learning and use of additional languages. 


\section{Current Trends And Future Directions}

Multilingualism includes both language learning and language use, which have both commonalities and differences in terms of history, present status, and future directions, and in terms of strategies for advocacy and promotion. While the role of multilingualism as a career, professional, and economic asset has been widely reported, the role of multilingualism in the development of a cosmopolitan identity and global citizenship values in the individual is also worthy of examination (ACTFL, 2019; NAE, 2017; Hogan-Brun, 2017).

Despite the increasing need for multilingualism in a globalized and interconnected world and in our increasingly multilingual and multicultural society, language learning in the US is facing challenges at all levels. In US public elementary and middle schools, the percentage of those offering language programs has declined in recent years, and foreign language enrollment has also declined in colleges and universities. Fewer than $20 \%$ of K-12 students study a foreign language, and only $7.5 \%$ of college and university students are enrolled in a course in a language other than English (American Councils, 2017; MLA, 2019). In the most recent period, 651 postsecondary programs were lost as defined by the report (MLA,2019).

Challenges to multilingualism have generally included the relative reluctance of Americans, and of Anglophones generally, to learn an additional language, believing that as English is the global lingua franca, it is not necessary for them to learn any additional languages. However, this widespread belief is erroneous, with only $25 \%$ of the world population able to speak English, and multilingualism the global norm, with at least $50 \%$ of the world population multilingual, using more than one language on a regular basis. In addition, it is important to remember that the underlying cause of the US foreign language deficit is actually the lack of opportunity for young Americans to learn another language rather than reluctance to do so. Only $15 \%$ of public elementary schools in the US offer foreign languages, and this number has actually decreased in recent years (AMACAD, 2017).

Despite this present situation, the proliferation of immersion programs demonstrates the interest of parents and students in language and cultural learning in an authentic setting where language is the medium of instruction rather than being considered a "foreign" language. In higher education, faculty have taken the lead in encouraging double majors and in developing interdisciplinary, pre-professional, and joint programs (MLA ). While the impending decline in enrollment due to the birth dearth, as well as the ongoing crisis in the humanities, have impacted colleges and universities, the most recent Humanities Indicators have indicated significant support among the public and among parents for language learning. While this support is strongest for language learning prior to college, a larger number of students with an interest in languages and the proficiency needed for pre-professional language study will be arriving on college campuses.

In terms of heritage languages, in addition to the increase in the number of immersion programs, communities and organizations have launched programs, events, and initiatives. Examples of these include the Oui! Initiative, promoting business use of French in Louisiana, as well as the development of French Language Job Fairs, both of which illustrate the concepts of francoresponsabilité and francodurabilité, the role of heritage language speakers in developing sustainable language use in authentic settings.

\section{Closing The Gap: Reducing The Foreign Language Deficit And EnCouraging Cosmopolitanism}

Just as the MLOW student winners developed action plans for implementing the Sustainable Development Goals (SDGs) in the their presentations in the UN General Assembly Hall, it is also necessary for those who believe in multilingualism to become advocates for language learning and use of other languages in the US, and "advocacy means to persuade people who matter to care about your issue" whether this means "getting listened to, being at the table when decisions are made, and being heard by people who make decisions", or "speaking and writing in compelling ways" in order to persuade and to influence (Daly, 2011, 15). Advocacy involves all language stakeholders -- educators and students, parents and communities, and business and government, using whatever means and methods are available -using face-to-face and online methods, and through research, writing, and professional engagement.

In order to reduce the foreign language deficit and to encourage cosmopolitanism, leadership among multilingual supporters is essential, as is a willingness to engage in social and political action. Supporters of cosmopolitanism, global citizenship, and multilingualism are also called upon to be leaders in their communities, educational institutions, and in our society. Advocates for multilingualism may need to exercise leadership, "a process whereby an individual influences a group of individuals to achieve a common goal" (Northouse, 2013, 5). The resurgence in foreign languages, multilingualism, and global citizenship in the US is also a social movement, meaning that various small groups of language stakeholders and supporters are united by the "shared purpose," of developing multilingualism, an international mindset, and global values in our society (Satell \& Popovic, 2017, web).

While the need for an international mindset in a globalized and interconnected world, and the role and significance of multilingualism in the development of global citizenship values are clear, the status of languages in the US is unclear. While many Americans (70M) speak a language other than English in the home, most American students do not learn additional languages in school. Increasing language learning and use in the US is a priority, and it is essential to expand access to language learning so that all interested students will have the opportunity to learn one or more additional 
languages and for continued language learning beginning in the earliest grades either through traditional foreign language instruction or through immersion programs.

Language advocacy, whose primary goal is to increase access and opportunity in order develop proficiency, needs to be a grassroots effort, including educators, parents and communities, heritage language groups, and language enterprise partners in business and government. In order to be effective, advocacy must incorporate methods from change management, psychology of influence and persuasion, social marketing, and public relations, as well as both traditional in-person and online methods. Advocacy also includes research, writing, and professional engagement, as well as support of advocacy initiatives at the local, regional, and national levels. The campaign for multilingualism transcends traditional language advocacy in its nature as a social movement, including social and political action. The implementation of a national language policy, which would foster and encourage multilingualism and support language learning and use, would be the most effective way to ensure both access and support.

\section{CONCLUSIONS}

While language learning and language use bring multiple benefits to the individual and to society, the role of multilingualism in developing a cosmopolitan identity and the values of global citizenship is essential, and multilingualism is an essential 21 st century skill. "To solve the problems we face, we must increase our capacity to speak with each other as part of a global community. Language instruction to enhance literacy and fluency, including knowledge of multiple languages, is crucial to creating future 'global citizens' who can respond to these challenges and support positive impacts on our own domestic politics" (AMACAD, 2020, 3).

Action steps include prioritizing language learning and language use in our schools and in society, through support of existing programs and initiatives and development of additional pathways to languages, "preparing present and future generations of citizens who will be responsible for building international collaborations and fostering harmony at home" (AMACAD, 2020, 3). Opportunity and access are critical issues, as is the cost of language learning for many around the world.

"Multilingualism is freedom" (Maher, 2017, 95), and effective advocacy needs to bring together language and international education advocates and activists from around the world in partnership with language stakeholders in science and technology, in global healthcare, in business, government, and many more, united in the shared purpose of a better world for all and languages for all.

\section{REFERENCES}

[1] Adams, J.M. \& Carfagna, A. (2006). Coming of Age in a Globalized World: The Next Generation. Westport, CT, Kumarian.

[2] American Academy of Arts and Sciences (AMACAD). (2017). America's Languages: Investing in Language Education for the 21st Century. https://www.amacad.org/publication/americas-languages (accessed 19/4/21).

[3] American Academy of Arts and Sciences (AMACAD). (2020). The Importance of Languages in Global Context: An International Call to Action. https://www.amacad.org/news/international-academies-language-education (accessed 19/4/21).

[4] American Council on the Teaching of Foreign Languages (ACTFL). (2019). Making Languages Our Business: Addressing Foreign Language Demand among US Employers. https://www.leadwithlanguages.org/language-advocacy/publications/ (accessed 19/4/21).

[5] American Councils on International Education. (2017). The National K-12 Foreign Language Enrollment Survey Report (accessed 19/4/21).

[6] Appiah, K.A. (2006). Cosmopolitanism: Ethics in a World of Strangers. NY: Norton.

[7] Brennan, T. (1997). At Home in the World: Cosmopolitanism Now. Cambridge, MA: Harvard.

[8] British Council. (2013). The English Effect. https://www.britishcouncil.org/research-policy-insight/policy-reports/the-englisheffect (accessed 19/4/21).

[9] Daly, J.A. (2011). Advocacy: Championing Ideas and Influencing Others. New Haven, CT: Yale.

[10] Devlin, K, (2015). Learning a foreign language a 'must' in Europe, not so in America https://www.pewresearch.org/facttank/2015/07/13/learning-a-foreign-language-a-must-in-europe-not-so-in-america/ (accessed 17/5/21).

[11] Devlin, K. (2018). Most European students are learning a foreign language in school while Americans lag. https://www.pewresearch.org/fact-tank/2018/08/06/most-european-students-are-learning-a-foreign-language-in-school-whileamericans-lag/ (accessed 19/4/21).

[12] Dornyei, Z. (1994). Motivation and Motivating in the Foreign Language. Classroom. The Modern Language Journal, v. 78, no. 3 (Autumn, 1994), pp. 273-284.

[13] Grosjean, F. (2010; 2020). Bilingualism's Best Kept Secret. https://www.psychologytoday.com/us/blog/lifebilingual/201011/bilingualisms-best-kept-secret (accessed 19/4/21).

[14] Grosjean, F. (2019). A Journey in Languages and Cultures: The Life of a Bicultural Bilingual. Oxford, UK: Oxford.

[15] Gunesch, K. (2003). Multilingualism and Cosmopolitanism. in Tokuhama-Espinosa, T., ed. The Multilingual Mind: Issues Discussed by, for, and about People Living with Many Languages. Westport, CT: Praeger.

[16] Gunesch, K. (2008). Multilingualism and Cosmopolitanism: Meanings, Relationships, Tendencies. Saarbrücken, Germany: VDM.

[17] Hogan-Brun, G. (2017). Linguanomics: What Is the Market Potential of Multilingualism? NY: Bloomsbury.

[18] Holborow, M. (2018). Language, commodification and labour: the relevance of Marx. Language Sciences v 70, 58-67

[19] Hu, J.C. (2018). Speaking a Second Language May Give Low-Income Kids a Boost. https://www.scientificamerican.com/article/speaking-a-second-language-may-give-low-income-kids-a- boost/_ (accessed 
$18 / 5 / 21)$.

[20] Kharkhurin, A. (2012). Multilingualism and Creativity. Bristol, UK: Multilingual Matters.

[21] Izadi, E. (2014). Bilingualism Can Help Close Learning Gaps for Immigrant Students. https://www.theatlantic.com/politics/archive/2014/04/bilingualism-can-help-close-learning-gaps-for-immigrantstudents/430875/ (accessed 18/5/21).

[22] Livermore, D. (2016). Driven by Difference: How Great Companies Fuel Innovation by Diversity. NY: AMACOM.

[23] Lüdi, G. \& Py, B. (2009). To be or not to be ... a plurilingual speaker. International Journal of Multilingualism v. 6 no. 2 , p. 154-167.

[24] Maher, J.C. (2017). Multilingualism: A Very Short Introduction. Oxford, UK: Oxford.

[25] McComb, C. (2001). About One in Four Americans Can Hold a Conversation in a Second Language. https://news.gallup.com/poll/1825/about-one-four-americans-can-hold-conversation-second- language.aspx (accessed 19/4/21).

[26] Modern Language Association (MLA). (2015). Data on Second Majors in Language and Literature: $2001-2013$. https://www.mla.org/Resources/Research/Surveys-Reports-and-Other-Documents/Teaching-Enrollments-and-Programs/Dataon-Second-Majors-in-Language-and-Literature-2001-13 (accessed 19/4/21).

[27] Modern Language Association (MLA). (2019). Enrollments in Languages Other Than English in United States Institutions of Higher Education. https://www.mla.org/Resources/Research/Surveys-Reports-and-Other-Documents/Teaching-Enrollmentsand-Programs/Enrollments-in-Languages-Other-Than-English-in-United-States-Institutions-of-Higher-Education (accessed 19/4/21).

[28] Montlaur, B. de. (2019). Do You Speak My Language? You Should. https://www.nytimes.com/2019/03/26/opinion/learnforeign-language.html (accessed 19/4/21).

[29] New American Economy. (NAE). (2017). Not Lost in Translation: U.S. Jobs Market Needs Foreign Language Skills. https://research.newamericaneconomy.org/report/not-lost-in-translation-the-growing-importance-of-foreign-language-skills-inthe-u-s-job-market/ (accessed 19/4/21).

[30] Northouse, P.G. (2013). Leadership: Theory and Practice, 6th ed. Thousand Oaks, CA: SAGE.

[31] Pardede, P. (2020). Integrating the 4Cs into EFL Integrated Skills Learning. https://files.eric.ed.gov/fulltext/EJ1266047.pdf (accessed 17/5/21).

[32] Pufahl, I., Rhodes, N.C., \& Christian, D. (2001). What We Can Learn from Foreign Language Teaching in Other Countries. https://eric.ed.gov/?id=ED456671 (accessed 18/5/21).

[33] Ross, J. F. (2019). Two Centuries of French Education in New York: The Role of Schools in Cultural Diplomacy. NY: TBR.

[34] Ryan, C. (2013). Language Use in the United States: 2011. https://www.census.gov/library/publications/2013/acs/acs-22.html (accessed 19/4/21).

[35] Satell, G. \& Popovic, S. (2017). How Protests Become Successful Social Movements. https://hbr.org/2017/01/how-protestsbecome-successful-social-movements (accessed 19/4/21).

[36] Stearns, P. N. (2008). Educating Global Citizens in Colleges and Universities: Challenges and Opportunities. NY: Routledge.

[37] United Nations. (2017). Many Languages One World. https://www.un.org/youthenvoy/2017/02/many- languages-one-worldstudent-essay-contest-deadline-16-march/ (accessed 19/4/21).

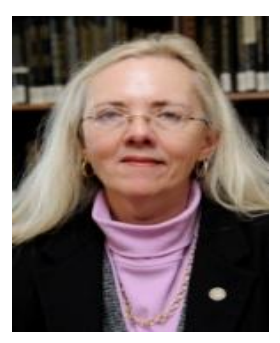

Kathleen Stein-Smith, $\mathrm{PhD}$, Chevalier dans l'Ordre des Palmes académiques, is a dedicated foreign language educator and advocate.

She serves as Chair of the AATF (American Association of Teachers of French) Commission on Advocacy and as a member of the ATA Education and Pedagogy Committee. She is also active in foreign language education associations, including the NECTFL Advisory Council, CSCTFL Advisory Council, and as a SCOLT sponsor.

She has presented at numerous professional conferences at the state, regional, and national level, is the author of five books and numerous articles about the foreign language deficit and the importance of multilingualism, has given a TEDx talk on the U.S. foreign language deficit, has been interviewed by press and radio, and maintains a blog, "Language Matters." 